\title{
Preparative Scale Organic Synthesis using a Kitchen Microwave Oven
}

\section{Shui-Tein Chen, Shyh-Horng Chiou, and Kung-Tsung Wang*}

Institute of Biochemical Sciences, National Taiwan University, and Institute of Biological Chemistry, Academia Sinica, P.O. Box 23-106, Taipei, Taiwan, ROC

A new and practical continuous flow procedure for preparative scale organic synthesis using a kitchen microwave oven as the heat source has been developed and successfully applied to five different organic reactions.

Microwave ovens have been used for moisture analysis, ${ }^{1}$ organic synthesis, ${ }^{2}$ acid decomposition of botanical or biological samples, ${ }^{3}$ and rapid hydrolysis of peptides and proteins. ${ }^{4}$ The rapid heating capability of the microwave oven leads to a considerable saving in dissolution or reaction time. The inherent hazard of violent explosion due to the high pressure and temperature developed in a closed vessel under microwave irradiation has limited the scale at which these rapid microwave reactions can be carried out to $<1 \mathrm{~g}$. We report here a continuous flow reaction process by which preparative scale samples $(>20$ g) may be synthesized safely. Five different types of organic reactions were studied: (i) the esterification of $p$-hydroxybenzoic acid with butan-1-ol and methanol, (ii) the racemization of optically pure amino acids in acetic acid, (iii) the acid hydrolysis of sucrose to glucose and fructose, (iv) the $S_{\mathrm{N}} 2$ reaction of phenoxide with benzyl chloride, and (v) the cyclization of butane-1,4-diol and of diethylene glycol.

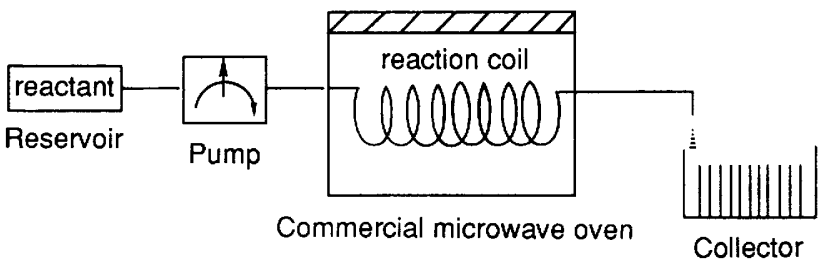

Figure 1. Schematic diagram of the continuous flow process using microwave irradiation.

Figure 1 shows the reaction diagram of the continuous flow system. The sample in the reservoir is pumped into a reaction coil in the microwave oven for irradiation, and then out to a product collector. A microwave oven with ten adjustable power settings operating at a frequency of $2450 \mathrm{MHz}$ and having a full-power level of $650 \mathrm{~W}$ was used for these experiments. A microwave-transparent Teflon tube was used 
Table 1. Summary of results of microwave heated reactions under closed vessel and continuous flow conditions.

\begin{tabular}{|c|c|c|c|c|c|c|}
\hline $\begin{array}{l}\text { Compounds } \\
\text { synthesized }\end{array}$ & Procedure & $\begin{array}{l}\text { Reaction time } \\
/ \text { min }^{\mathrm{a}}\end{array}$ & $\begin{array}{c}\text { Power } \\
\text { setting }\end{array}$ & $\begin{array}{c}\text { Reaction } \\
\text { quantity } \\
/ \mathrm{mmol}\end{array}$ & $\begin{array}{c}\text { Conversion } \\
/ \%\end{array}$ & $\begin{array}{c}\text { Efficiencyc } \\
\qquad / \%\end{array}$ \\
\hline \multicolumn{7}{|c|}{ Esterification of $p$-hydroxybenzoic acid with butan-1-ol and methanol } \\
\hline $\mathrm{HOC}_{6} \mathrm{H}_{4} \mathrm{CO}_{2} \mathrm{C}_{4} \mathrm{H}_{9}$ & Closed vessel & 5.0 & 2 & 1 & 89 & - \\
\hline, & Continuous flow & 1.0 & 3 & 100 & 12 & 13 \\
\hline ”, & , & 2.0 & 2 & 100 & 29 & 32 \\
\hline , & , & 3.0 & 2 & 100 & 53 & 59 \\
\hline$"$ & , & 4.0 & 2 & 100 & 67 & 64 \\
\hline , & , & 5.0 & 4 & 100 & 81 & 90 \\
\hline, & , & 6.0 & 3 & 200 & 89 & 100 \\
\hline $\mathrm{HOC}_{6} \mathrm{H}_{4} \mathrm{CO}_{2} \mathrm{Me}$ & Closed vessel & 3.0 & 4 & 1 & 82 & - \\
\hline, & Continuous flow & 3.0 & 5 & 100 & 46 & 56 \\
\hline , & Continuous flow ${ }^{d}$ & 4.0 & 3 & 240 & 58 & 70 \\
\hline \multicolumn{7}{|c|}{ Racemization of $L$-amino acids in acetic acide } \\
\hline $\mathrm{D}, \mathrm{L}$-Isoleucine & Closed vessel & 2.0 & 2 & 1 & 100 & - \\
\hline , & Continuous flow & 1.0 & 3 & 50 & 60 & 60 \\
\hline, & & 2.0 & 3 & 300 & 100 & 100 \\
\hline D,L-Phenylalanine & Closed vessel & 2.0 & 1 & 1 & 100 & - \\
\hline, & Continuous flow & 0.5 & 2 & 50 & 7 & 7 \\
\hline ," & ,, & 1.0 & 3 & 50 & 29 & 29 \\
\hline , & ,, & 1.5 & 3 & 50 & 89 & 89 \\
\hline , & , & 2.0 & 3 & 200 & 100 & 100 \\
\hline \multicolumn{7}{|c|}{ Hydrolysis of sucrose to glucose and fructose } \\
\hline Glucose + fructose & Closed vessel & 10.0 & 2 & 1 & 95 & _- \\
\hline, & Continuous flow & 10.0 & 2 & 200 & 93 & 95 \\
\hline$"$ & Continuous flow ${ }^{f}$ & 10.0 & 2 & 200 & 95 & 100 \\
\hline \multicolumn{7}{|c|}{ Cyclization of butane-1,4-diol and diethylene glycol } \\
\hline Tetrahydrofuran & Closed vessel & 4.0 & 3 & 1 & 95 & - \\
\hline & Continuous flow & 4.0 & 4 & 200 & 95 & 100 \\
\hline Dioxaneg & Closed vessel & 4.5 & 6 & 1 & 37 & - \\
\hline , & Continuous flow & 6.0 & 7 & 180 & 35 & 97 \\
\hline, &, & 8.0 & 6 & 180 & 43 & $>100$ \\
\hline \multicolumn{7}{|c|}{$S_{\mathrm{N}} 2$ reaction of phenoxide with benzyl chloride } \\
\hline $\mathrm{PhOCH}_{2} \mathrm{Ph}$ & Closed vessel & 10.0 & 8 & 1 & 49 & - \\
\hline, & Continuous flow & 10.0 & 8 & 100 & 49 & 100 \\
\hline
\end{tabular}

a In the continuous flow processes the reaction time is equal to the irradiation time. ${ }^{\mathrm{b}}$ According to the operation manual the power setting of each number is $1: 36,2: 72,3: 143,4: 215,5: 286,6: 358,7: 430,8: 500,9: 572,10: 650 \mathrm{~W}$. $^{c}$ Calculated on the basis of the $\%$ conversion obtained by closed vessel system. ${ }^{d}$ Xylene-methanol $(1: 1)$ was used as the reaction cosolvent to improve the yield of conversion. ${ }^{e}$ Change in optical purity was measured by polarimetry and HPLC using a Diacel chiral column. ${ }^{f}$ Using acid cation-exchange resin (Doulite C25D, ROHM \& HAAS) as catalyst. $\mathrm{g}$ Some side products were present in both reactions, \% conversion measured by GC.

as the sample-carrying system and continuous-flow container for reactants and products. The total volume of the Teflon coil is about $10 \mathrm{ml}$. The reactions were carried out under the continuous flow process and also in a sealed Teflon vessel as previously reported. 4 The products of these microwave heated reactions were analysed by HPLC or GC methods and the reaction efficiencies for both processes were calculated and compared.

Table 1 shows the results for each reaction tested by these microwave processes. The concentrations of various reactants were kept the same under both sets of reaction conditions. Reaction products were identified by their melting and boiling points, and NMR and IR spectra. In the continuous flow reaction, the reaction time is actually equal to the irradiation time of the sample in the reaction coil of the microwave oven. The retention time of the sample in the coil can be controlled by adjusting the flow rate of the pump. As shown in Table 1, the conversion of $p$-hydroxybenzoic acid and butan-1-ol to butyl $p$-hydroxybenzoate increased with the irradiation time in the microwave oven. This is true for all five reactions studied, and the percentage conversion can be controlled by adjusting the irradiation time. The pressure inside the reaction coil during the reaction process is higher than atmospheric pressure owing to the positive pressure from the pump plus the induced pressure increment from irradiation. Most of the reactions tested in the continuous flow system generally have a higher conversion efficiency compared with those conducted in a closed vessel system within the same time period of irradiation. All reactions were run safely without explosion or charring except the cyclization of diethylene glycol to dioxane, the solution of the final products turning black after reaction. In the esterification of $p$-hydroxybenzoic acid with methanol, the yield is low for the continuous flow process due to the evaporation of methanol in the Teflon coil which resulted in solution spillage. The substitution of xylene-methanol $(1: 1)$ for methanol as the cosolvent improves the conversion by $25 \%$. It is also of interest to note that the hydrolysis of sucrose using a strong acid cation-exchange resin as catalyst gives a better result than that using mineral acid.

In conclusion, these preparative-scale pilot experiments using the continuous flow process have demonstrated the feasibility of applying microwave technology to large scale organic synthesis for industrial use. Of particular interest are the following observations. (i) The potential reaction hazard 
of closed-vessel microwave heating can be avoided by using a continuous flow process. (ii) The use of ion-exchange resins as catalysts for the conversion of sucrose to glucose and fructose under microwave irradiation may be able to compete with the industrial operation currently achieved by immobilizedenzyme processes. ${ }^{5}$ (iii) Continuous flow microwave irradiation has been shown to be an inexpensive process for the conversion of unwanted optical enantiomers into their racemic mixtures for further enrichment and recovery of useful enantiomers. 6

Received, 12th March 1990; Com. 0/01084G

\section{References}

1 J. A. Hesek and R. C. Wilson, Anal. Chem., 1974, 46, 1160.
2 R. Gedye, F. Smith, K. Westaway, H. Ali, L. Baldisera, L. Laberge, and J. Rousell, Tetrahedron Lett., 1986, 27, 278; R. J. Giguere, T. L. Bray, S. M. Duncan, and G. Majetich, ibid., 1986, 27, 4945; A. B. Alloum, B. Labiad, and D. Villemin, J. Chem. Soc., Chem. Commun., 1989, 386; K. Chatakondu, M. L. H. Green, D. M. P. Mingos, and S. M. Reynolds, ibid., 1989, 1515; S. T. Chen, S. H. Wu, and K. T. Wang, Int. J. Pept. Protein Res., 1989, 33, 73; R. N. Gedye, F. E. Smith, and K. Westaway, Can. J. Chem., 1988, 66, 17.

3 H. M. Kingston and L. B. Jassie, Anal. Chem., 1986, 58, 2534.

4 S. T. Chen, S. H. Chiou, Y. H. Chu, and K. T. Wang, Int. J. Pept. Protein Res., 1987, 30, 572; H. M. Yu, S. T. Chen, S. H. Chiou, and K. T. Wang, J. Chromatogr., 1988, 456, 357; S. H. Chiou and K. T. Wang, J. Chromatogr. Biomed. Applications, 1989, 491, 424.

$5 \mathrm{H}$. H. Weetall, in 'Immobilized enzyme for industrial reactor,' ed. R. A. Messing, Academic Press, New York, San Francisco, London, 1985.

6 P. E. Sonnet, Chem. Tech., 1988, 94, and references cited therein. 